Cahiers $d u$ MONDE RUSSE

\section{Cahiers du monde russe}

Russie - Empire russe - Union soviétique et États indépendants

$44 / 4 \mid 2003$

Varia

\title{
Elena Dundovich, Francesca Gori, Emanuela Guercetti, eds., Reflections on the Gulag
}

\section{Nicolas Werth}

\section{OpenEdition}

\section{Journals}

Édition électronique

URL : https://journals.openedition.org/monderusse/4119

DOI : 10.4000/monderusse.4119

ISSN : $1777-5388$

Éditeur

Éditions de l'EHESS

\section{Édition imprimée}

Date de publication : 1 octobre 2003

Pagination : 750-753

ISBN : 2-7132-1833-0

ISSN : $1252-6576$

Référence électronique

Nicolas Werth, «Elena Dundovich, Francesca Gori, Emanuela Guercetti, eds., Reflections on the Gulag », Cahiers du monde russe [En ligne], 44/4 | 2003, mis en ligne le 19 juin 2009, consulté le 03 septembre 2022. URL : http://journals.openedition.org/monderusse/4119; DOI : https://doi.org/ 10.4000/monderusse.4119

Ce document a été généré automatiquement le 3 septembre 2022.

Tous droits réservés 


\title{
Elena Dundovich, Francesca Gori, Emanuela Guercetti, eds., Reflections on the Gulag
}

\author{
Nicolas Werth
}

\section{RÉFÉRENCE}

Elena DUNDOVICH, Francesca GORI, Emanuela GUERCETTI, eds., Reflections on the Gulag. With a documentary appendix on the Italian victims of repression in the USSR. Milan, Fondazione Feltrinelli, 2003, 700 p.

1 Fruit d'une longue collaboration entre la Fondation Feltrinelli et l'Association Memorial, cet ouvrage aux multiples entrées (bibliographie, articles de synthèse, articles spécialisés, recueils de documents) est à la fois un formidable instrument de travail et un état précis des lieux de la recherche sur le Goulag. Il permet de mesurer l'immense progrès accompli depuis une dizaine d'années dans la connaissance des divers cercles du système répressif stalinien, longtemps fondée sur les seuls témoignages des survivants. Mais aussi de prendre la mesure de la complexité des problèmes historiographiques que pose une approche multiple du phénomène concentrationnaire soviétique (histoire des politiques répressives, de l'administration du Goulag, histoire sociale du Goulag, histoire économique du Goulag, mémoire et histoire du Goulag).

Particulièrement bienvenue est la remarquable bibliographie commentée, de plus de 600 titres, présentée par Hélène Kaplan et accompagnée d'un essai sur l'historiographie du Goulag, les principaux types de sources récemment déclassifiées et leurs apports. Parmi les sources encore peu exploitées figurent notamment les lettres envoyées -le plus souvent illégalement - par les détenus à leur famille, et conservées dans les archives de Memorial. Cette source, présentée par Ania Morozova, s'avère précieuse pour appréhender le quotidien du camp et faire contrepoids à une vision trop exclusivement bureaucratique de cette réalité. Analysant avec finesse l'évolution de la littérature de 
témoignage sur l'expérience « goulaguienne » depuis les années 1960, Irina Shcherbakova montre la cohérence fondamentale de ces textes écrits par une catégorie très précise de détenus (intellectuels, membres du parti), non représentative de l'immense diversité de la «nation zek». Malgré ses limites et ses distorsions (cette littérature a longtemps accrédité l'idée selon laquelle les cadres du Parti, les militaires et les intellectuels avaient constitué les principaux contingents des victimes de la Ežovščina), cette source, qui s'est considérablement enrichie, depuis la fin des années 1980, de témoignages oraux conservés notamment dans les archives de l'Association Memorial, reste incontournable. En effet, souligne Irina Shcherbakova, dans les archives bureaucratiques du Goulag, qui sont d'abord la " mémoire du système ", l'individu tend à disparaitre, il est transformé en « poussière du camp ».

3 Un second ensemble de contributions apporte des synthèses stimulantes sur des questions centrales de l'histoire du Goulag. Nikita Petrov retrace la mise en place, puis l'expansion du système des camps de travail forcé de 1918 à 1939, un thème plus longuement développé dans d'autres publications récentes de l'auteur ${ }^{1}$. L'aggravation de la répression, qui se traduisait par un brusque afflux de détenus, perturbait souvent la bonne gestion économique des camps: à partir de ce constat, fait pour les années 1937-1938, Nikita Petrov analyse les importantes réformes du système concentrationnaire, initiées en 1939 par Berija. La synthèse de Marta Craveri sur le travail forcé en Union soviétique de 1939 à 1956 retrace l'enchaînement qui conduit le Goulag de l'apogée à la crise. Dans ce processus, l'arrivée de nouveaux contingents de détenus, véritables opposants au système stalinien (« nationalistes » ukrainiens et baltes) joue un rôle au moins aussi important que l'incapacité du système concentrationnaire à remplir les objectifs de production qui lui sont assignés et à assurer une " rentabilité » minimale. Des pages remarquables sont consacrées à l'analyse des diverses formes de " résistance » au Goulag au début des années 1950.

4 La contribution de Pavel Polian, qui porte sur les répressions staliniennes contre les étrangers, reprend pour partie (notamment dans les passages concernant les minorités ethniques déportées) des éléments développés par l'auteur dans sa magistrale synthèse, Ne po svoej vole (Moscou, 2001, Ed. OGI-Memorial). Les aspects les plus nouveaux de cette contribution concernent les ressortissants étrangers au Goulag (une trentaine de milliers en 1950) et l'internement, dans les camps du GUPVI, de civils allemands déportés, de fin 1944 à avril 1945, des différents pays d'Europe centrale et orientale occupés par l'Armée rouge. Sur les 300000 déportés, la moitié disparurent en quelques mois! L'intérêt et la nouveauté de cette recherche pâtissent cependant de la structure générale de l'article, qui juxtapose, sous le titre "Soviet repression of foreigners", des réalités très différentes: déportations collectives, sur simple mesure politico-administrative, de citoyens soviétiques appartenant à une minorité ethnique; condamnations individuelles de citoyens étrangers à une peine de camp, au titre de l'article 58 du Code pénal; déportation et internement de civils d'une puissance ennemie dans un contexte de guerre.

5 C'est une histoire plus strictement politique que développe, dans un remarquable article fondé sur une documentation inédite, Fridrick Firsov ( $"$ The Komintern and Stalin's Terror »). Firsov analyse notamment le fonctionnement du Département des cadres et ses liens avec l'OGPU-NKVD, ainsi que le rôle central de la Commission internationale de contrôle dans les purges de l'organisation. L'essentiel de l'article est, en effet, consacré aux mécanismes des purges au sein du Komintern, commencées dès 1935 et poursuivies 
jusqu'en 1938-1939, ainsi qu'aux diverses catégories successivement visées : émigrés politiques, notamment polonais, allemands et italiens ; militants politiques soupçonnés d'avoir participé à un mouvement oppositionnel au sein des partis communistes nationaux ; enfin, à partir de 1937, cadres mêmes du Komintern. Ces purges spécifiques sont replacées dans le contexte général de la "Grande Terreur ", marquée, on le sait, par une double orientation répressive - l'une fondée sur des critères "traditionnels" prenant en compte l'origine sociale des " éléments socialement nuisibles" à éliminer; l'autre basée sur une nouvelle "xénophobie soviétique " (Terry Martin), prenant pour cible un certain nombre de diasporas et de "nationalités ennemies ", au premier rang desquelles figuraient les émigrés politiques polonais, allemands, baltes, ainsi que les citoyens soviétiques d'origine polonaise, allemande, balte, etc.

6 Un accent particulier est mis, dans ce recueil d'articles, sur le sort de la petite communauté italienne installée notamment en Ukraine et en Crimée depuis le xix ${ }^{\mathrm{e}}$ siècle. La contribution érudite de Elena Dundovich, Francesca Gori et Emanuela Guercetti évoque la progressive marginalisation de cette communauté commerçante dans les années 1920, analyse les transformations de celle-ci avec l'arrivée d'émigrés politiques anti-fascistes, et fait le point sur les répressions politiques dont furent victimes près d'un millier d'Italiens qui avaient cru trouver dans l'URSS stalinienne un refuge. Ceux qui échappèrent aux purges de la fin des années 1930 furent, au cours de la guerre, déportés (ainsi l'entière communauté italienne de Kertch) comme "ressortissants d'un État en guerre contre l'URSS $»$. Cette étude est complétée par une très importante annexe biographique de plusieurs centaines de ressortissants et d'émigrés italiens condamnés à une peine de camp, la plupart sur la base de l'article 58 du Code pénal (« activités contrerévolutionnaires») et par des procès-verbaux d'interrogatoires d'Italiens arrêtés en 1938-1939.

7 Au total, ce gros recueil est un ouvrage foisonnant, qui ouvre un nombre considérable de pistes de recherche, tout en apportant aux non-spécialistes des outils bibliographiques et documentaires indispensables.

\section{NOTES}

1. Voir notamment A. I. Kokurin, N. V. Petrov, eds., Gulag, 1917-1960, Moscou, Meždunarodnyj Fond « Demokratija », 2000. 